\title{
Shakedown for slab track substructures with stiffness variation
}

Shu Liu BEng, MSc, PhD

Research Fellow, Ningbo Nottingham New Materials Institute, University of Nottingham Ningbo China, Ningbo, China

Juan Wang BEng, MSc, PhD

Assistant Professor, Ningbo Nottingham New Materials Institute, University of Nottingham Ningbo China, Ningbo, China (corresponding author: juan.wang@nottingham.edu.cn)
Hai-Sui Yu BE, DIC, MSc, DPhil, DSc, CEng, FICE, FREng Professor, School of Civil Engineering, Faculty of Engineering, University of Leeds, Leeds, UK

Dariusz Wanatowski MSc, PhD, CEng, CSci, MIMMM, FICE

Professor, School of Civil Engineering, Faculty of Engineering, University of Leeds, Leeds, UK

In this paper, shakedown analyses are carried out to predict the long-term response of slab track substructures under repeated moving train loads. The train loads are converted into a distributed moving load on the substructure surface by using a simplified track analysis. Based on Melan's static shakedown theorem, a well-established shakedown analysis method is extended to determine shakedown limits of the slab track substructures. The influence of a linearly increasing stiffness modulus on the shakedown limits is considered by conducting finiteelement analysis with a user-defined material. It is found that a rise in stiffness modulus or stiffness variation ratio can either increase or decrease the shakedown limit, depending on the competitive effects of the two mechanisms. Furthermore, the subgrade thickness determines the dominant mechanism.

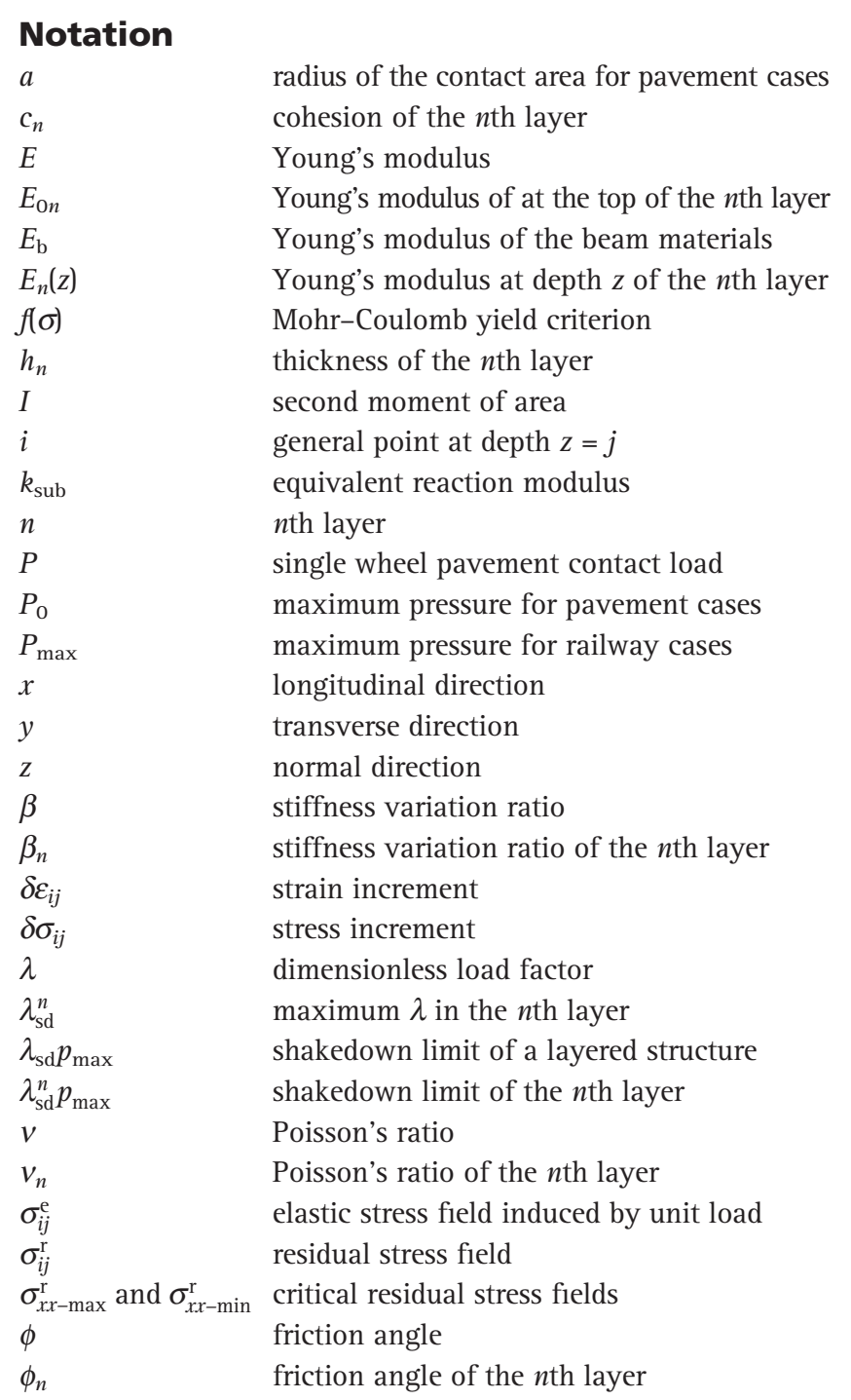

\section{Introduction}

The good performance of a slab track requires very limited post-construction settlement or differential settlement which is a consequence of permanent deformation. Great efforts on material quality and compaction level have been made to try to address this issue. However, predicting the train-load-induced settlement is still found to be very difficult.

Recently, the theory of shakedown has been successfully applied in the field of pavement engineering to design against excessive rutting (Collins and Cliffe, 1987; Liu et al., 2016; Ponter et al., 1985; Sharp and Booker, 1984; Wang and Yu, 2013a, 2013b, 2014; Yu, 2006; Yu and Hossain, 1998; Yu and Wang, 2012). Shakedown is concerned with the ultimate response of an elastic-plastic structure subjected to cyclic or repeated loads. When the applied cyclic load is high, the elastic-plastic structure will fail due to excessive settlement or alternative plasticity. However, when the applied load is lower than a 'shakedown limit' but higher than the yield limit, the structure will adapt itself to the cyclic loads and finally perform elastically to the subsequent load cycles. If the latter situation occurs, the structure reaches a relatively stable state, termed as a 'shakedown status'. The essence of the application of the shakedown theory is to determine the shakedown limit, which can be used to guide engineering design against excessive permanent deformation. For the slab track problem, the shakedown theory can be used to predict the long-term behaviour of the substructures under repeated moving train loads.

Shakedown limits can be determined directly using Melan's static shakedown theorem (Melan, 1938) or Koiter's kinematic shakedown theorem. By using one of the shakedown theorems, a lower bound or an upper bound to the actual shakedown limit can be obtained (e.g. Collins and Cliffe, 1987; Ponter et al., 1985; Sharp and Booker, 1984; Yu and Hossain, 1998; Yu and Wang, 
2012). An advantage of using these two fundamental shakedown theorems is that the details of the successive elastic-plastic stress histories are not required. Recently, a three-dimensional (3D) lower-bound shakedown analysis method has been developed by Yu and Wang (2012) for pavement problems. The results have been verified by comparing with numerical step-by-step analyses (Liu et al., 2016; Wang and Yu, 2013a).

In the present study, the method of Yu and Wang (2012) will be extended to solve the railway slab track problems. For the track problem, the influencing depth of the train load is much larger than the pavement problem. Therefore, the effect of the depthdependent soil stiffness will be considered.

\section{Slab track problem}

Figure 1 shows a typical slab track system which includes a superstructure and a supporting substructure. The superstructure includes the rail, track slab, concrete base, sleeper, pad and fastening system. Table 1 summarises the properties of the key components of the superstructure. The dimensions of the track slab and the concrete base are taken from a typical Rheda 2000 single-track system. The rail is UIC60. The substructure is made of granular materials and soils. It is assumed that the stiffness modulus of the subsoil varies linearly with depth $z$

1. $E(z)=E_{0}(1+z \beta)$

where $E_{0}$ indicates the stiffness modulus at the subsoil surface; $E(z)$ indicates the stiffness modulus at a depth $z$ from the subsoil surface; and $\beta$ is a stiffness variation ratio. This kind of soil is known as a Gibson-type soil (Gibson, 1967). This Gibson soil has been widely applied to solve footing problems (Boswell and Scott, 1975; Stark and Booker, 1997). Moreover, the granular materials and soils are assumed to be elastic-perfectly plastic, following the Mohr-Coulomb criterion.

Four axle loads belonging to two adjacent bogies on two carriages are considered in the analysis. Each axle load is denoted by $\lambda P$, where $P$ is a unit axle load and $\lambda$ is a scale factor. It is assumed that the loads move at a constant speed along the $x$-direction (Figure 1). Also, the train speed is much less than the critical speed of the track structure; therefore, this problem can be considered as a quasi-static one.

\section{Lower-bound shakedown analysis approach}

Melan's lower-bound shakedown theorem

Melan's static shakedown theorem states that an elastic-perfectly plastic structure under cyclic or variable loads will shake down if a self-equilibrated residual stress field exists such that its superposition with a load-induced elastic stress field does not exceed the yield criterion anywhere in the structure. According to the theorem, three components are essential for the calculation of the shakedown limit, which are the elastic stress field, residual stress field and yield criterion.

\section{Shakedown analysis}

Yu and Wang (2012) proposed an approach to obtaining the lowerbound shakedown limits of cohesive-frictional materials under 3D surface loads. The approach was developed by considering that one of the $x-z$ planes is critical ( $x$ is the travel direction, and $z$ is the vertical direction). On these planes, only the horizontal residual stresses can exist since boundary and equilibrium conditions eliminate the possibility of other residual stresses. Moreover, using the Mohr-Coulomb yield criterion and the self-equilibrium condition of the residual stress field, it is found the actual horizontal residual stress must be fully bracketed by the following two critical residual stress fields when the structure is at a shakedown status
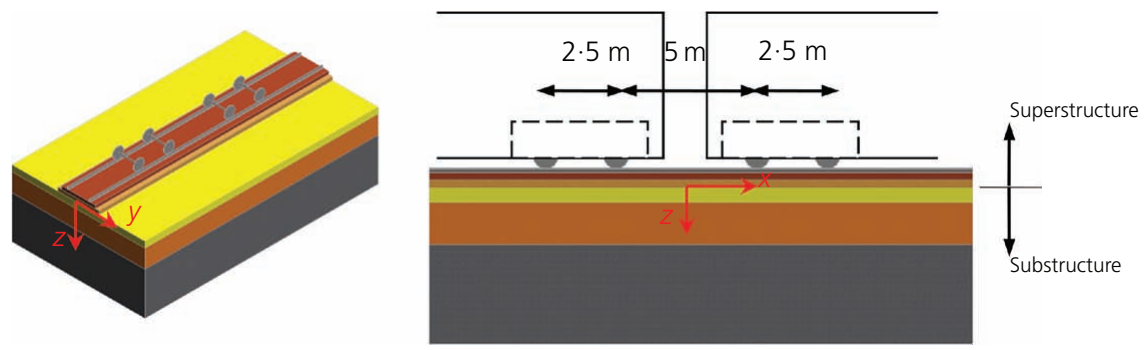

Figure 1. A typical slab track structure and axle loads

Table 1. Material properties of the superstructure

\begin{tabular}{lccccc} 
Layer & Young's modulus, $E_{\mathbf{b}}: \mathbf{G P a}$ & Width: $\mathbf{c m}$ & Height: $\mathbf{c m}$ & Second moment of area, $\mathbf{l}: \mathbf{c m}^{\mathbf{4}}$ & Mass per unit length: $\mathbf{k g} / \mathbf{m}$ \\
\hline Rail & 210 & 15 & $17 \cdot 2$ & 3055 & $60 \cdot 03$ \\
Track slab & 34 & 280 & 24 & 322560 & 1680 \\
Concrete base & 10 & 340 & 30 & 765000 & 2448
\end{tabular}




$$
\begin{aligned}
\sigma_{x x-\min }^{\mathrm{r}} & =\min _{z=j}\left(-M_{i}+\sqrt{-N_{i}}\right) \\
\text { 2. } \quad \sigma_{x x-\max }^{\mathrm{r}} & =\max _{z=j}\left(-M_{i}-\sqrt{-N_{i}}\right)
\end{aligned}
$$

with

$$
\begin{aligned}
M & =\lambda \sigma_{x x}^{\mathrm{e}}-\lambda \sigma_{z z}^{\mathrm{e}}+2 \tan \phi_{n}\left(c_{n}-\lambda \sigma_{z z}^{\mathrm{e}} \tan \phi_{n}\right) \\
\text { 3. } \quad N & =4\left(1+\tan ^{2} \phi_{n}\right)\left[\left(\lambda \sigma_{x z}^{\mathrm{e}}\right)^{2}-\left(c_{n}-\lambda \sigma_{z z}^{\mathrm{e}} \tan \phi_{n}\right)^{2}\right]
\end{aligned}
$$

in which $i$ represents a general point at depth $z=j ; \phi$ is the material friction angle; $c$ is the material cohesion; $\sigma_{i j}^{\mathrm{e}}$ is the elastic stress field induced by a unit axial load $P$; and the subscript $n$ $(n=1,2,3, \ldots)$ means the $n$th layer. Tension positive notation is applied throughout this paper.

By substituting the load-induced elastic stress fields and either of the critical residual stress fields into the Mohr-Coulomb yield criterion $f(\sigma) \leq 0$, the present shakedown problem can be rewritten as a mathematical optimisation problem

$\max \lambda$

4.

$$
\begin{array}{ll}
\text { s.t. } & f\left[\sigma_{x x}^{\mathrm{r}}\left(\lambda \sigma^{\mathrm{e}}\right), \lambda \sigma^{\mathrm{e}}\right] \leq 0 \\
& \sigma_{x x}^{\mathrm{r}}\left(\lambda \sigma^{\mathrm{e}}\right)=\sigma_{x x-\max }^{\mathrm{r}} \text { or } \sigma_{x x-\min }^{\mathrm{r}}
\end{array}
$$

For a layered structure, one maximum admissible load factor $\lambda$ can be found for each layer, marked as $\lambda_{\mathrm{sd}}^{n}$; therefore, $\lambda_{\mathrm{sd}}^{n} P$ is the shakedown limit of the $n$th layer. The minimum value among all $\lambda_{\mathrm{sd}}^{n} P$ is then recorded as the shakedown limit of the whole structure. The mathematical optimisation problem can be solved using a program developed by Wang and Yu (2013b) using Matlab.

For the problem of slab track, the preceding shakedown analysis can be applied to the substructures provided that the pressure applied on the substructures and the train-induced elastic stress fields are known.

\section{Simplified track analysis for pressure distribution}

A simplified track analysis is proposed to convert the train loads to a distributed moving pressure on the substructure. It is considered that the superstructure components act together as a single infinite Euler-Bernoulli beam with a total $E_{\mathrm{b}} I$ value $\left(E_{\mathrm{b}}\right.$ is the Young's modulus of the beam materials; $I$ is the second moment of the inertia of the beam), while the supporting substructure is simplified as a Winkler's foundation. The pads and sleepers are ignored in this study as they barely contribute to the bending of the superstructure. Winkler's hypothesis, despite its obvious limitations, yields reasonable performance (Dutta and Roy, 2002; Kouroussis et al., 2011). The displacement of the beam $\Delta$ can be easily obtained using exiting solutions (e.g. Frýba, 1972). And the reaction pressure on the substructure can be calculated provided that a reaction modulus $k(\mathrm{MPa} / \mathrm{m})$ is known

$$
\text { 5. } p=k \Delta
$$

Based on the beam on elastic foundation analysis (Esveld, 2001), the reaction pressure can be written as

$$
\text { 6. } p=p_{0} e^{-\mu|x|}[\cos \mu(x)+\sin \mu|x|]
$$

where $p_{0}=\lambda P \mu / 4 b ; \mu=\left(2 k b / E_{\mathrm{b}} I\right)^{0 \cdot 25}$; and $b$ is the half-width of the beam.

It should be noted that the reaction modulus is not a fundamental soil property. Relations between the reaction modulus and the material elastic modulus have been proposed theoretically or empirically by a number of authors for different situations (e.g. Biot, 1937; Sadrekarimi and Akbarzad, 2009; Vesic, 1961). It was suggested that the nature of the supporting elastic medium can be best described by the deflection line of its surface under a unit concentrated load (Dutta and Roy, 2002). For the problem of an infinite beam resting on a $3 \mathrm{D}$ elastic soil continuum, Vesic (1961) developed a relation between the reaction modulus $k$ and the elastic modulus of the soil $E$ by equating the maximum deflection of the beam with the maximum surface displacement of the elastic half-space; however, the proposed equation is obtained for $b / d$ smaller than 1 , where $d$ is defined as

$$
\text { 7. } d=\left[\frac{\left(1-v^{2}\right) E_{\mathrm{b}} I}{E}\right]^{1 / 3}
$$

in which $v$ is the Poisson's ratio of the soil. Vesic's (1961) equation deviates from the exact solutions when $b / d$ is close to or higher than 1 . The current slab track analysis, however, has a relatively large value of $b / d$, varying between 1 and 3 . Therefore, a new equation (Equation 8) is derived following Vesic's fitting method (Vesic, 1961). This fitting method matches the shape of the deflection curve obtained by considering a beam resting on a 3D elastic-isotropic continuous half-space (Vesic, 1961) with that obtained from beam on elastic foundation analysis. The results have been validated by comparing with corresponding displacements from finite-element (FE) analyses, as shown in Figure 2.

8. $k=\frac{0 \cdot 583 E_{\mathrm{b}} I}{b^{1 \cdot 267} d^{3 \cdot 733}}$

As a result, the four unit axle loads are converted into a distributed load on the top of the substructure, as shown in 
Shakedown for slab track substructures

with stiffness variation

Liu, Wang, Yu and Wanatowski

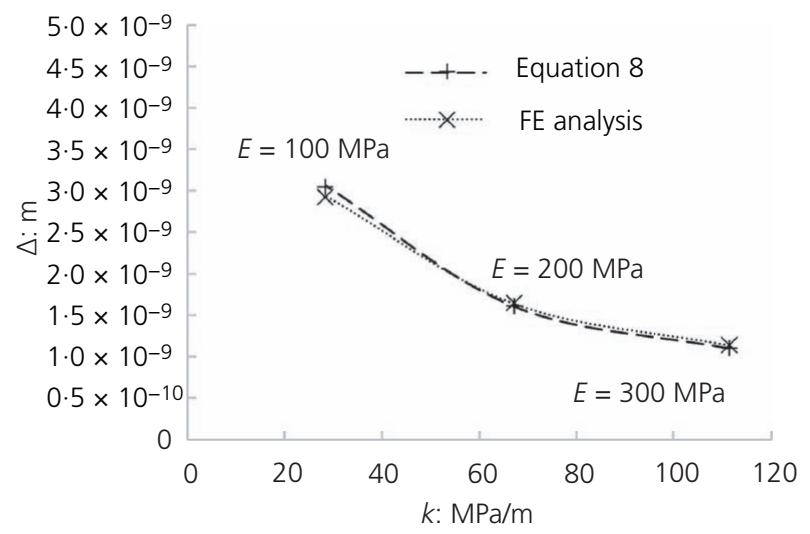

Figure 2. Comparison of maximum surface deflections under a unit $P$

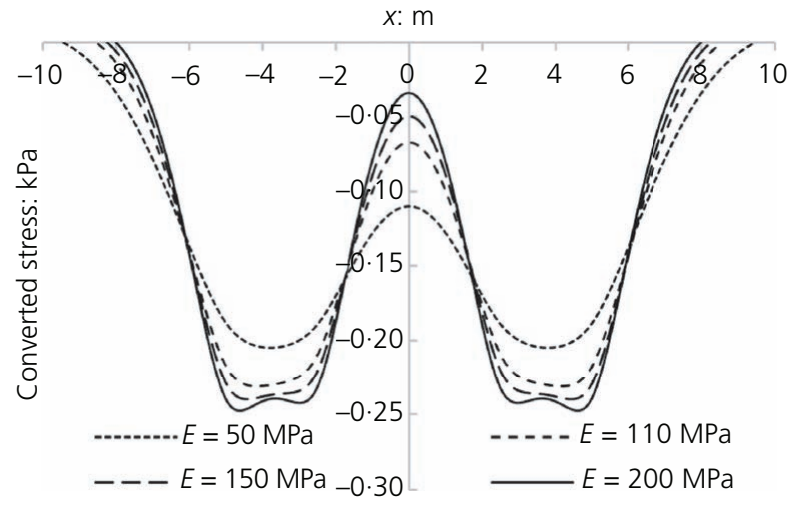

Figure 3. Effect of stiffness modulus on pressure distribution

Figure 3 for different values of the stiffness modulus. The reaction force due to the upward displacement of the beam is taken as zero. As can be seen, the pressure is distributed more widely and uniformly when the reaction modulus is lower. In the transverse direction, the pressure is assumed to be distributed uniformly over the width of the concrete base (i.e. $3 \cdot 4 \mathrm{~m})$.

In practice, the substructure is made of layers of materials. For such kind of layered problem, it is practical to use an
Table 2. Material properties of three-layered substructures

\begin{tabular}{|c|c|c|c|c|c|}
\hline Layer name & $h_{n}: m$ & $\begin{array}{c}E_{n} \text { or } E_{n 0}: \\
\mathrm{MPa}\end{array}$ & $v_{n}$ & $\phi_{n}:^{\circ}$ & $c_{n}: \mathrm{kPa}$ \\
\hline $\begin{array}{l}\text { Antifrozen } \\
\text { layer }\end{array}$ & 0.4 & 200 & 0.3 & 50 & 1 \\
\hline $\begin{array}{l}\text { Prepared } \\
\text { subgrade }\end{array}$ & $1 \cdot 3,1 \cdot 8,2 \cdot 3,2 \cdot 8$ & 130 & 0.3 & 40 & 2 \\
\hline Subsoil & $\infty$ & $\begin{array}{r}110 \\
55\end{array}$ & $\begin{array}{l}0.3 \\
0.3\end{array}$ & $\begin{array}{l}30 \\
30\end{array}$ & $\begin{array}{l}2 \\
2\end{array}$ \\
\hline
\end{tabular}

equivalent reaction modulus $k_{\mathrm{eq}}$ or an equivalent stiffness modulus $E_{\text {eq. }}$. However, the exiting methods are more suitable for footing problems (e.g. Cai et al., 1994; Sadrekarimi and Akbarzad, 2009; Sridharan et al., 1990) rather than for the slab track problem. A matching procedure is thus proposed based on the fact that the maximum surface displacement of the substructure equals the maximum deflection of the beam on an equivalent Winkler's foundation. The matching procedure has been validated by comparing the pressure distributions at design situations to those measured in field and model tests of Bian et al. (2014). In the present study, a three-layered substructure consisting of an antifrozen layer, a prepared subgrade layer and subsoil with great depth is considered. Five cases are considered as listed in Table 2. The corresponding equivalent $k_{\text {eq }}$ values are determined according to Figure 4. The load distributions on the layered substructures can be obtained by substituting $k_{\text {eq }}$ into Equation 6.

Meanwhile, the load distributions for the cases with depthdependent stiffness are determined in a similar manner by matching the maximum displacements. It should be noticed that the stiffness variation is considered only for the subsoil layer. Finally, a relation between $k_{\mathrm{eq}}$ and $\beta$ is given in Figure 5. As can be seen, the equivalent reaction modulus $k_{\text {eq }}$ increases nonlinearly with the stiffness variation ratio. Figure 6 also compares the load distributions for $\beta=0$ and $\beta=1$.

\section{Elastic stress fields}

As for the elastic stress fields, numerical calculations are required to obtain solutions. In this study, FE analyses using the commercial software Abaqus are conducted. The stress-strain relation (Equation 2) considering the depth-dependent stiffness is programmed into a UMAT subroutine and integrated with the software.

9. $\left[\begin{array}{c}\delta \varepsilon_{x x} \\ \delta \varepsilon_{y y} \\ \delta \varepsilon_{z z} \\ \delta \varepsilon_{x y} \\ \delta \varepsilon_{x z} \\ \delta \varepsilon_{y z}\end{array}\right]=\left[\begin{array}{cccc}1 /\left(E_{0}+E_{0} \beta z\right) & -v /\left(E_{0}+E_{0} \beta z\right) & -v /\left(E_{0}+E_{0} \beta z\right) \\ -v /\left(E_{0}+E_{0} \beta z\right) & 1 /\left(E_{0}+E_{0} \beta z\right) & -v /\left(E_{0}+E_{0} \beta z\right) \\ -v /\left(E_{0}+E_{0} \beta z\right)-v /\left(E_{0}+E_{0} \beta z\right) & 1 /\left(E_{0}+E_{0} \beta z\right) & \\ & (1+v) /\left(E_{0}+E_{0} \beta z\right) & \\ & (1+v) /\left(E_{0}+E_{0} \beta z\right) & \\ & (1+v) /\left(E_{0}+E_{0} \beta z\right)\end{array}\right]\left[\begin{array}{c}\delta \sigma_{x x} \\ \delta \sigma_{y y} \\ \delta \sigma_{z z} \\ \delta \sigma_{x y} \\ \delta \sigma_{x z} \\ \delta \sigma_{y z}\end{array}\right]$ 
Shakedown for slab track substructures

with stiffness variation

Liu, Wang, Yu and Wanatowski

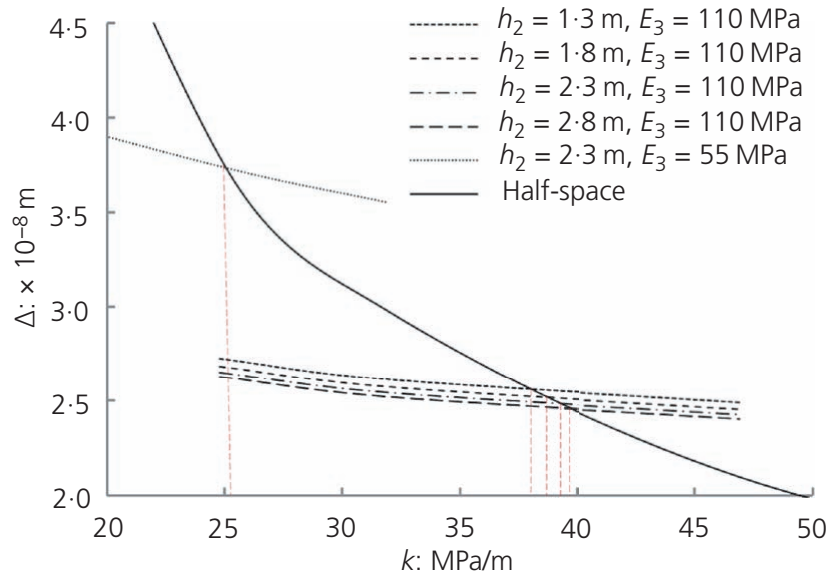

Figure 4. Determination of $k_{\text {eq }}$ for layered substructures

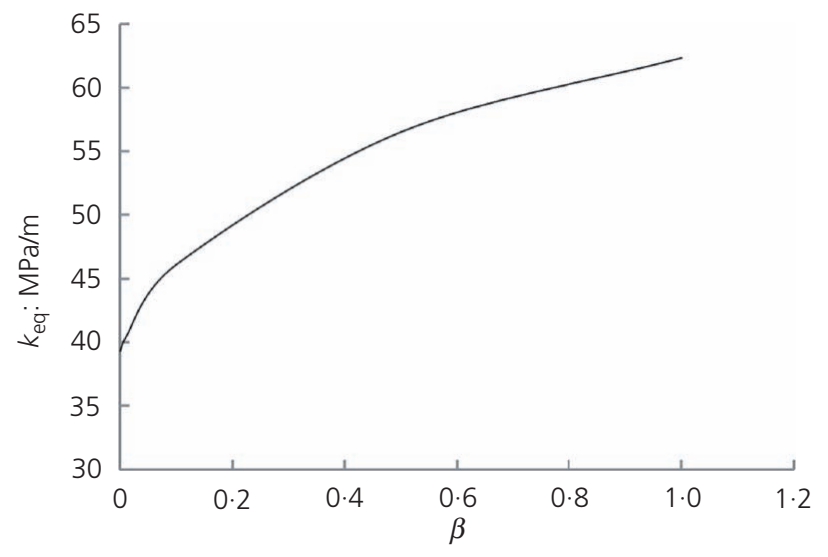

Figure 5. Relation between $k_{\text {eq }}$ and $\beta$

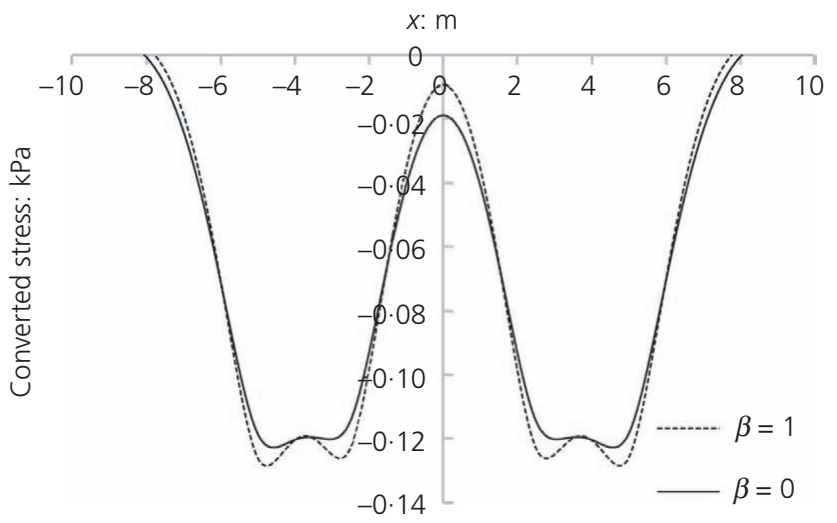

Figure 6. Effect of stiffness variation ratio on pressure distribution
The FE model is shown in Figure 7. Only a quarter of the substructure is built by assigning symmetric boundary conditions on the $x-z$ plane and $y-z$ plane (Figure 7). The fine mesh density is used for the regions near these two symmetric planes and the interfaces between different layers. The load distribution on the substructure is controlled by the user subroutine DLOAD. Sensitivity studies have been carried out to examine the effects of the model size and element type. It is found that the model size has an obvious effect on the shakedown limit; therefore, a very large model with size $300 \mathrm{~m} \times 50 \mathrm{~m} \times 50 \mathrm{~m}$ is selected. Comparatively, the effect of the element type (C3D8 and C3D20R) is negligible. C3D8 is finally chosen considering the computational cost. The FE model is validated by comparing the present lowerbound shakedown solutions with the analytical shakedown solutions of Wang et al. (2018) for a homogenous case.

\section{Lower-bound shakedown limits}

Shakedown limits for a homogeneous half-space

Shakedown limits for an isotropic homogenous half-space subjected to different load distributions (Figure 8) are first presented. The shakedown limits are normalised by the cohesion $c$. As can be seen, a higher friction angle gives a larger shakedown limit. Also, the shakedown limit varies with the stiffness modulus, giving a maximum difference of $37 \%$. This is because the reaction modulus $k$ as well as the load distribution is changed. When the stiffness modulus is high, the load is distributed more narrowly, leading to a relatively uneven pressure. This finally results in higher stresses close to the surface and increases the possibility of failure.

\section{Shakedown limits for a layered substructure}

Figure 9 shows the shakedown limits of each layer for a threelayered structure considering $\beta=0$. It is found that an increase in the subgrade thickness (second layer) decreases the shakedown limit of that layer but increases those of the other two layers. More significant changes can be observed in the subsoil (third layer). It should be noted that for any specific case, the lowest layer shakedown limit is the overall shakedown limit of the substructure. It is interesting to notice that there exists an optimum layer thickness, around $1.7 \mathrm{~m}$ in this particular case. A further increase in the subgrade thickness barely changes the overall shakedown limit.

Figure 10 further examines the influence of the stiffness modulus on the shakedown limit while keeping the ratios of stiffness moduli of layers $E_{1} / E_{2} / E_{3}$ unchanged. All stiffness moduli are increased by around $45 \%$, and the corresponding load distributions are calculated. Compared with Figure 9, this case shows similar changing tendencies of the layer shakedown limits; however, the optimum layer thickness is moved to around $2.2 \mathrm{~m}$ (Figure 10). Also, the rises in the stiffness moduli reduce the substructure shakedown limit for low $h_{2}$ cases, but increase it for high $h_{2}$ cases. This difference is attributed to the fact that the pressure distribution is changed. For the cases with higher stiffness, the pressure is less evenly distributed, leading to a lower 


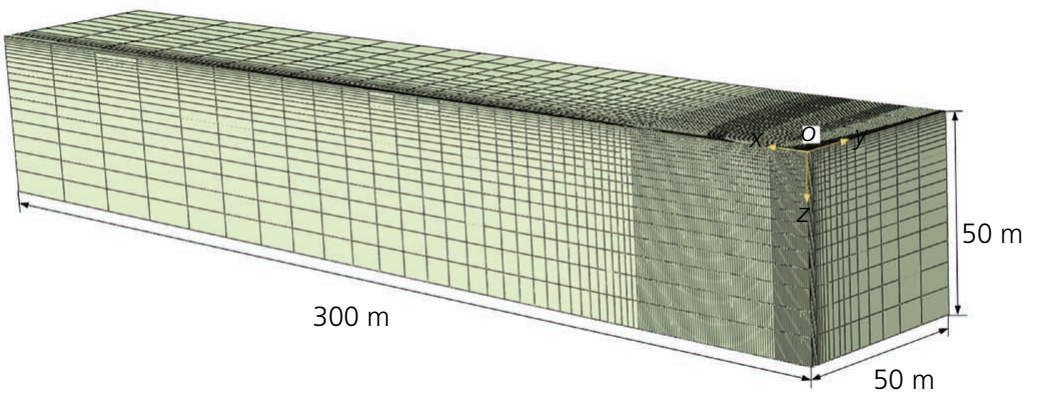

Figure 7. FE model

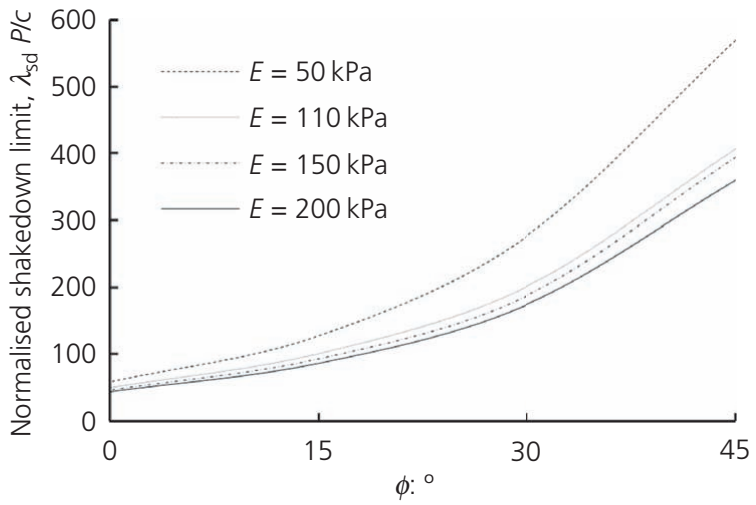

Figure 8. Shakedown limits for a homogeneous half-space

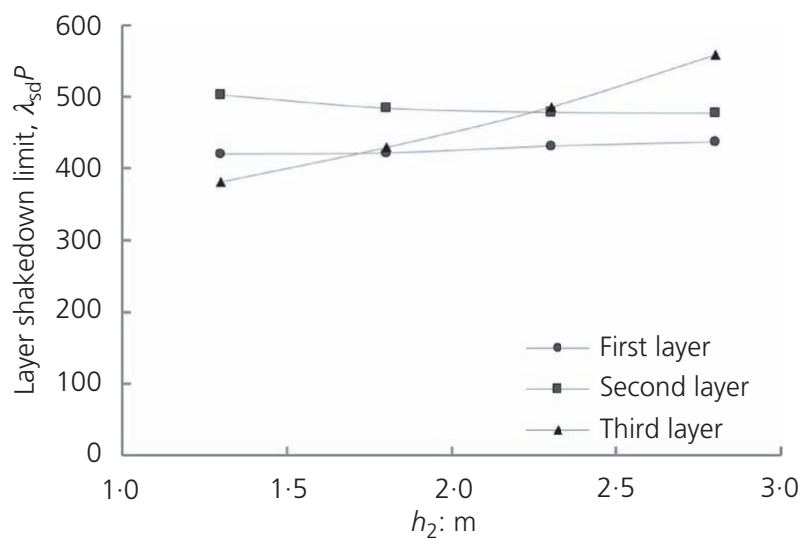

Figure 9. Effect of subgrade thickness on layer shakedown limits when $E_{1}=200 \mathrm{MPa}, E_{2}=130 \mathrm{MPa}$ and $E_{3}=110 \mathrm{MPa}$

shakedown limit of the first layer and higher shakedown limits of the other layers. When the subgrade thickness is small, the subsoil becomes critical, resulting in an upward trend. When the subgrade thickness is large, the other two layers tend to fail first. Figure 11 summarises the effects of stiffness modulus and subgrade thickness on the overall shakedown limits. It should be noted that if the pressure distribution is also kept identical, the shakedown

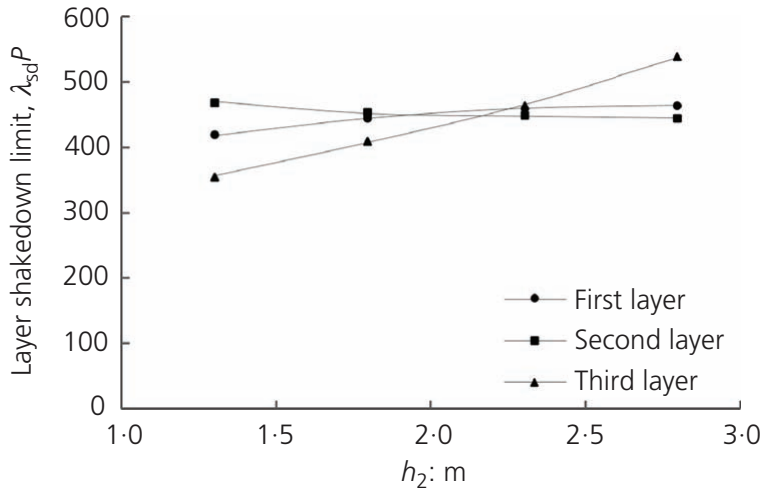

Figure 10. Effect of subgrade thickness on layer shakedown limits when $E_{1}=290 \mathrm{MPa}, E_{2}=190 \mathrm{MPa}$ and $E_{3}=160 \mathrm{MPa}$

limit should not change because the elastic stress distribution will be the same according to Wang and Yu (2013b).

Figure 11 also shows the result of a soft subsoil case (only the subgrade stiffness is halved) in which the shakedown limit is decreased significantly. The layer shakedown limits for the soft case are 220, 290 and $572 \mathrm{kN}$. This implies that a poor-soil ground will result in more stresses locked in the upper layers and thus a higher possibility of large permanent deformation. Overall, any decrease of material stiffness modulus involves two mechanisms: more evenly distributed pressure due to a weaker substructure and changed elastic distribution due to the modified stiffness ratios.

The results for the cases when the depth-dependent stiffness is considered for the subsoil and $h_{2}=2 \cdot 3 \mathrm{~m}$ are shown in Figure 12 . The layer shakedown limits are also competitively affected by the two mechanisms mentioned earlier.

First, the rise in the stiffness variation ratio $\beta$ means that the overall stiffness of the substructure is increased, so the pressure distribution tends to be more uneven as shown in Figure 6. This leads to higher local stresses close to the surface and thus a lower shakedown limit of the first layer (Figure 12). This is verified by searching for the 
Shakedown for slab track substructures

with stiffness variation

Liu, Wang, Yu and Wanatowski

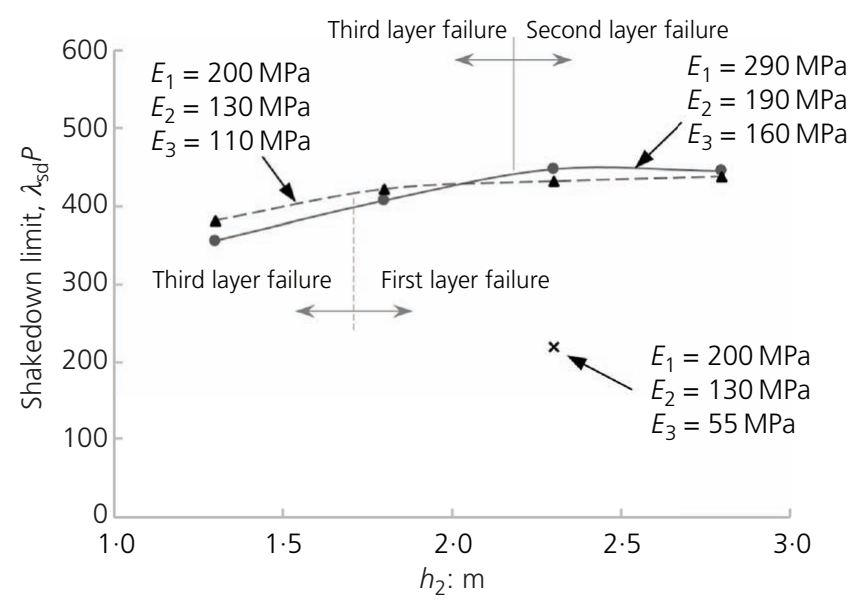

Figure 11. Effect of stiffness modulus on substructure shakedown limits

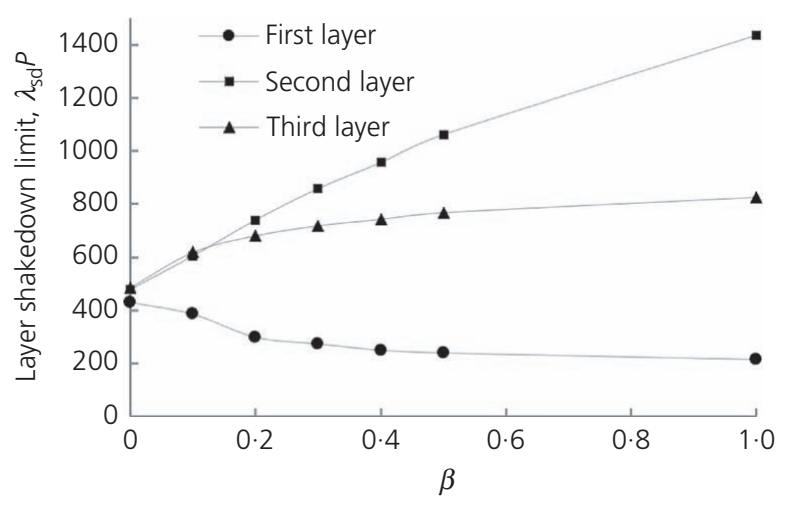

Figure 12. Effect of stiffness variation ratio on layer shakedown limits

critical point of the layer. The locations of the critical points in each layer are shown in Figure 13 at which two critical residual stress fields intersect. As can be seen, when $\beta$ is increased from 0 to 1 , the critical point location is switched from the subsurface to the surface due to higher pressures on surface. Meanwhile, the stresses transferred to the lower two layers are relatively small, leading to downward trends of the layer shakedown limits.

Secondly, the rising $\beta$ also gives decreasing ratios of layer stiffness $E_{1} / E_{3}$ and $E_{2} / E_{3}$. As a result, fewer stresses will be contained in the upper two layers and more stresses will be taken by the third layer. The shakedown limit of the third layer then tends to decrease, while those of the upper two layers tend to increase.

Consequently, both mechanisms strengthen the second layer, demonstrated as a fast growth of its shakedown limit. In the current case with a relatively thick subgrade $\left(h_{2}=2.3 \mathrm{~m}\right)$, the influence of the first mechanism overwhelms that of the second, leading to a decreasing trend for first layer but an increasing trend for the third layer. (a)

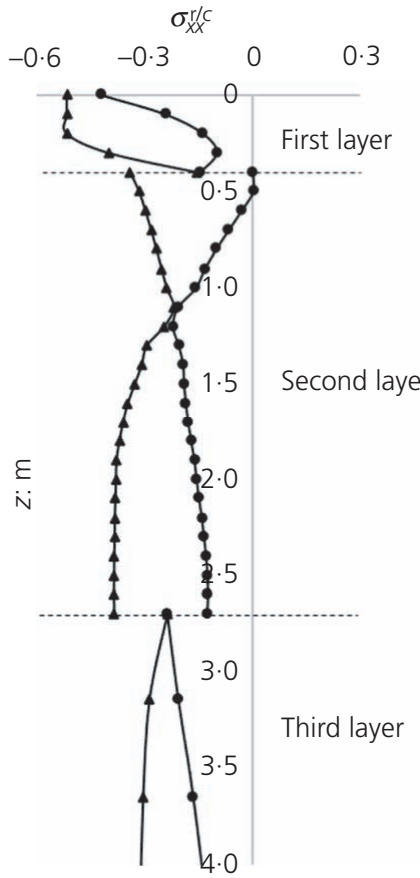

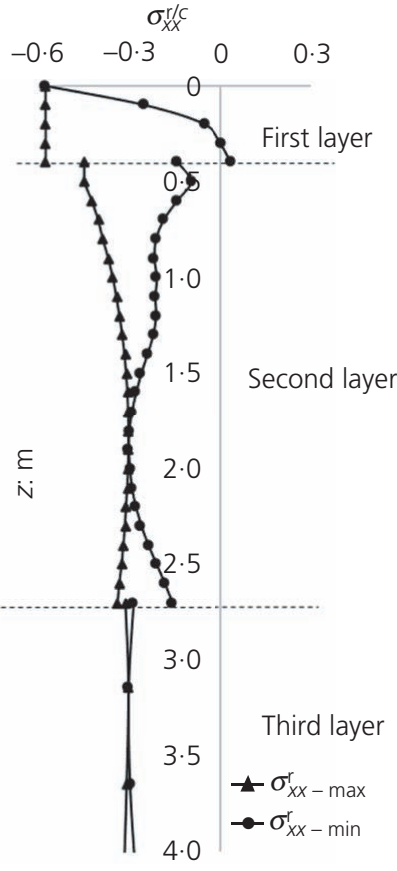

(b)
Figure 13. Normalised critical residual stress fields: (a) $\beta=0$; (b) $\beta=1$

\section{Conclusions}

In this paper, the lower-bound shakedown solutions for substructures of slab tracks have been obtained. A simplified method is developed to convert the train load on the superstructure to a moving pressure on the substructure. The key influencing factors are investigated, including the depth-dependent stiffness variation ratio for the subsoil.

It is found that the change in the shakedown limit with the rising stiffness modulus or the increasing stiffness variation ratio $\beta$ is competitively controlled by two mechanisms. First, the pressure distribution becomes relatively uneven, leading to higher stresses at the surface, a smaller shakedown limit of the first layer and larger shakedown limits of the lower layers. Second, the ratios of layer stiffness $E_{1} / E_{3}$ and $E_{2} / E_{3}$ become lower, resulting in more stresses in the third layer and a lower shakedown limit of that layer. Accordingly, there are more stresses in the upper layers; therefore, the corresponding layer shakedown limits are higher.

If the subgrade is thin, the second mechanism dominates the overall shakedown limit; otherwise, the first one is in control. For a typical three-layered substructure, an increase in the subgrade thickness will raise the overall shakedown limit until an optimum value is reached which represents the transfer of critical point location from the subsoil to one of the upper layers.

Overall, the material stiffness modulus (including the depthdependent stiffness modulus), the ratios of layer stiffness and the 
layer thickness have great impacts on the long-term stability of the slab track substructure. A proper design should have considered all those effects and should have reached the maximum potentials of each layer.

\section{Acknowledgements}

Financial supports from the National Natural Science Foundation of China (Grant Number 51408326) and the Ningbo 3315 Talent Scheme are gratefully acknowledged.

\section{REFERENCES}

Bian XC, Jiang HG, Cheng C et al. (2014) Full-scale model testing on a ballastless high-speed railway under simulated train moving loads. Soil Dynamics and Earthquake Engineering 66: 368-384.

Biot M (1937) Bending of an infinite beam on an elastic foundation. Journal of Applied Mechanics 59: A1-A7.

Boswell LF and Scott CR (1975) A flexible circular plate on a heterogeneous elastic half-space: influence coefficients for contact stress and settlement. Géotechnique 25(3): 604-610.

Cai Z, Raymond GP and Bathurst RJ (1994) Estimate of static track modulus using elastic foundation models. Transportation Research Record 1470: 65-72.

Collins IF and Cliffe PF (1987) Shakedown in frictional materials under moving surface loads. International Journal for Numerical and Analytical Methods in Geomechanics 11(4): 409-420.

Dutta SC and Roy RA (2002) A critical review on idealization and modeling for interaction among soil-foundation-structure system. Computers and Structures 80(20-21): 1579-1594.

Esveld C (2001) Modern Railway Track, 2nd edn. MRT Productions Duisburg, Germany.

Frýba L (1972) Vibration of Solids and Structures under Moving Loads. Noordhoff International, Groningen, the Netherlands.

Gibson RE (1967) Some results concerning displacements and stresses in a non-homogeneous elastic half-space. Géotechnique 17(1): 58-67.

Kouroussis G, Verlinden O and Conti C (2011) Free field vibrations caused by high-speed lines: measurement and time domain simulation. Soil Dynamics and Earthquake Engineering 31(4): 692-707.

Liu S, Wang J, Yu HS and Wanatowski D (2016) Shakedown solutions for pavements with materials following associated and non-associated plastic flow rules. Computers and Geotechnics 78: 218-266.
Melan E (1938) Der spannungsgudstand eines Henky-Mises schen kontinuums bei verlandicher belastung. Sitzungberichte der Ak Wissenschaften Wie 147: 73-87 (in German).

Ponter ARS, Hearle AD and Johnson KL (1985) Application of the kinematical shakedown theorem to rolling and sliding point contacts. Journal of the Mechanics and Physics of Solids 33(4): 339-362.

Sadrekarimi J and Akbarzad M (2009) Comparative study of methods of determination of coefficient of subgrade reaction. Electronic Journal of Geotechnical Engineering 14(s1-s6): 211-216.

Sharp RW and Booker JR (1984) Shakedown of pavements under moving surface loads. Journal of Transportation Engineering 110(1): 1-14.

Sridharan A, Gandhi NSVVSJ and Suresh S (1990) Stiffness coefficients of layered soil systems. Journal of Geotechnical Engineering 116(4): 604-624.

Stark RF and Booker JR (1997) Surface displacements of a non-homogeneous elastic half-space subjected to uniform surface tractions: part I: loading on arbitrarily shaped areas. International Journal for Numerical and Analytical Methods in Geomechanics 21(6): 361-378.

Vesic AB (1961) Bending of beams resting on isotropic elastic solid. Journal of Engineering Mechanics 87(2): 35-54.

Wang J, Liu S and Yang W (2018) Dynamics shakedown analysis of slab track substructures with reference to critical speed. Soil Dynamics and Earthquake Engineering 106: 1-13.

Wang J and Yu HS (2013a) Residual stresses and shakedown in cohesivefrictional half-space under moving surface loads. Geomechanics and Geoengineering 8(1): 1-14.

Wang J and Yu HS (2013b) Shakedown analysis for design of flexible pavements under moving loads. Road Materials and Pavement Design 14(3): 703-722.

Wang J and Yu HS (2014) Three-dimensional shakedown solutions for anisotropic cohesive-frictional materials under moving surface loads. International Journal for Numerical and Analytical Methods in Geomechanics 38(4): 331-348.

Yu HS (2006) Plasticity and Geotechnics. Springer, New York, NY, USA.

Yu HS and Hossain MZ (1998) Lower bound shakedown analysis of layered pavements using discontinuous stress fields. Computer Methods in Applied Mechanics and Engineering 167(3-4): 209-222.

Yu HS and Wang J (2012) Three-dimensional shakedown solutions for cohesive-frictional materials under moving surface loads. International Journal of Solids and Structures 49(26): 3797-3807.

\section{How can you contribute?}

To discuss this paper, please submit up to 500 words to the editor at journals@ice.org.uk. Your contribution will be forwarded to the author(s) for a reply and, if considered appropriate by the editorial board, it will be published as a discussion in a future issue of the journal. 